\title{
Scanning Electron Microscope Evaluation of Smear Layer Removal at the Coronal, Middle, and Apical Third of Root Canals using Er,Cr:YSGG Laser: An in vitro Study
}

\author{
${ }^{1}$ Sabari Murugesan, ${ }^{2}$ Rajasekaran M, ${ }^{3}$ Veni Ashok Baskaran, ${ }^{4}$ Shankar Narayan Gopal, ${ }^{5}$ Indra R, ${ }^{6}$ Ramachandran S
}

\begin{abstract}
The aim of the study was to analyse the smear layer removal at the coronal,middle and apical third of the root canals by using $\mathrm{Er}$, Cr; YSGG laser system equipped with conical tip of $300 \mu \mathrm{m}$. A total of 80 single rooted extracted human mandibular premolars were endodontically prepared with rotary instrumentation and irrigated with $5.25 \%$ sodium hypochlorite and were randomly divided in to four groups (20 tooth each). GROUP I: Served as control (non lased group), in which root canal were irrigated with 17\% EDTA .GROUP II : 17\% EDTA irrigant activated by laser with conical fibre tip at the coronal region .GROUP III: $17 \%$ EDTA irrigant activated by laser with conical fibre tip at the middle region.GROUP IV: $17 \%$ EDTA irrigant activated by laser with conical fibre tip at the apex region. The results showed complete smear layer removal at the coronal and middle region when compared to apical third of the root canal system.
\end{abstract}

Keywords: Er, Cr: YSGG Laser, Root canals, Scanning electron microscope, Smear layer.

How to cite this article: Murugesan $S$, Rajasekaran $M$, Baskaran VA, Gopal SN, Indra R, Ramachandran S. Scanning Electron Microscope Evaluation of Smear Layer Removal at the Coronal, Middle, and Apical Third of Root Canals using Er,Cr:YSGG Laser: An in vitro Study. J Oper Dent Endod 2017;2(1):11-14.

Source of support: Nil

Conflict of interest: None

\section{INTRODUCTION}

The ability to successfully treat and remove the smear layer and bacteria continues to be a challenge in nonsurgical endodontic treatment of the root canal system. The shaping and cleaning of root canals is a key step during root canal treatment, and unless all remnants of debris are removed, subsequent stages of obturation may also be jeopardized. ${ }^{1}$ Clinically, endodontic procedures use both mechanical instrumentation and chemical irrigants in an

\footnotetext{
${ }^{1}$ Senior Lecturer, ${ }^{2}$ Professor, ${ }^{3,4}$ Reader, ${ }^{5}$ Former Head and Professor, ${ }^{6}$ Former Principal and Professor

${ }^{1-4}$ Department of Conservative Dentistry and Endodontics Ragas Dental College \& Hospital, Chennai, Tamil Nadu, India

${ }^{5,6}$ Private Practitioner, Chennai, Tamil Nadu, India

Corresponding Author: Sabari Murugesan, Senior Lecturer Department of Conservative Dentistry and Endodontics, Ragas Dental College \& Hospital, Chennai, Tamil Nadu, India, Phone: +919843745412, e-mail: pg.sabari@gmail.com
}

attempt to three-dimensionally debride, clean, and decontaminate the endodontic system. ${ }^{2}$ Some of these irrigation techniques include manual irrigation with needles and cannulas, the use of machine-assisted agitation systems, and sonic and ultrasonic energy sources. All file systems generate a smear layer and leave debris in the root canal. Irrigation with $5.25 \%$ sodium hypochlorite alone is unable to remove debris and smear layer. Other irrigants, such as $2 \%$ chlorhexidine gluconate, $17 \%$ ethylenediaminetetraacetic acid (EDTA), and 10\% citric acid have been used to remove debris, but many studies have demonstrated the limited ability to effectively reach all internal faces of seemingly complicated root canal architecture. ${ }^{3}$

Recent studies have shown excellent ability of a new file system operated with a continuous irrigation device to remove debris and smear layer from the apical third of the root canal. The literature shows that when compared with coronal and middle thirds of relatively clean canal, the apical third of a root canal always presents a problem with regard to the ability to achieve the same cleanliness. This fact may be of significance during root canal treatment because the presence of smear layer and debris may prevent sealer adaptation to the canal walls and impede penetration of irrigants into dentinal tubules and accessory canals. Accordingly, the same alternative, more effective method to debride, clean, and penetrate the dentinal walls should be explored. ${ }^{4}$

The effectiveness of laser in dentistry continues to be an area of discussion. However, the use of lasers for nonsurgical endodontic treatment of the root canal system has been reported since the early 1970s. ${ }^{5}$ A common feature of dissatisfaction has been the thermal damage associated with the application of laser photonic energy. ${ }^{6}$ The erbium, chromium: Yttrium-scandium-gallium-garnet (Er,Cr:YSGG) laser is approved by the Food and Drug Administration for cleaning, shaping, and enlarging the root canal. ${ }^{7}$ Previous studies have tested the ability and effects of this laser on root canal walls and have indicated that the Er,Cr:YSGG laser is a suitable instrument for the removal of smear layer in root canals. Furthermore, George et $\mathrm{al}^{8}$ investigated the ability of Er,Cr:YSGG lasers equipped with conical firing tips to remove smear layer from apical third of the root canal and showed a laser activation of EDTA and better performance of conical 
fiber tips for improving the action of EDTA in removing smear layer.

The aim of our study was to evaluate the effectiveness of smear layer removal by Er,Cr:YSGG laser irradiation applied through a radial firing fibre tip with a diameter of $300 \mu \mathrm{m}$.

\section{MATERIALS AND METHODS}

\section{Sample Preparation}

In this study, 80 recently extracted single-rooted human mandibular premolars were used and stored in physiological saline until use. The teeth were radiographed to confirm the absence of complicated root canal anatomy, after the crowns were removed at the level of cementoenamel junction by a diamond disk.

\section{ROOT CANAL PREPARATION}

The working length was determined by measuring the length of a \#10 K-file passively inserted into the canal until it was visible at the apex and then backing off by $1 \mathrm{~mm}$. Canals were prepared with ProTaper (Maillifer, Dentsply, Ballaigues, Switzerland) rotary nickel-titanium instruments to a working length $1 \mathrm{~mm}$ short of the apex to size F3 in a crown down technique. Canals were irrigated with a 23-gauge needle ( $3 \mathrm{~mL}$ ) alternatively with $5.25 \% \mathrm{NaOCl}$ and $3 \%$ hydrogen peroxide $\left(\mathrm{H}_{2} \mathrm{O}_{2}\right)$ after each instrumentation. Finally, an irrigation with $3 \mathrm{~mL}$ of distilled water was used to avoid the development of $\mathrm{NaOCl}$ crystals. The root canals were dried with absorbent points.

\section{LASER PARAMETERS}

The Waterlase MD laser (Biolase) was used at panel settings of $1.5 \mathrm{~W}$ average power and $20 \mathrm{~Hz}(62.5 \mathrm{~mJ} /$ pulse $)$ and was delivered into a $300 \mu \mathrm{m}$ (size ISO 30) conical tip endodontic fiber. No air or water spray was used. The fiber tip was fixed in a handpiece of an Er,Cr:YSGG laser.

\section{LASER IRRADIATION AND IRRIGATION METHODS}

After the mechanical preparation, teeth were randomly divided into four groups (20 teeth each) and treated according to the following protocols:

Group I (GI): Served as control (nonlased group)

Group II (GII): 17\% EDTA irrigant activated by laser with conical fiber tip at the coronal region.

Group III (GIII): 17\% EDTA irrigant activated by laser with conical fiber tip at the middle region.

Group IV (GIV): 17\% EDTA irrigant activated by laser with conical fiber tip at the apex region.

During irradiation cycles, the conical laser fiber tip was inserted into the root canal and then activated for
5 seconds. Treatment was undertaken for four passes of 5 seconds. Each pass was done at a fiber withdrawal rate of $1 \mathrm{~mm} / \mathrm{sec}^{8}$

\section{Scanning Electron Microscope EXAMINATION}

Teeth were grooved longitudinally with a diamond disk on their buccal and lingual surfaces and split into two halves with chisel. Split specimens were gold sputtered and subjected to scanning electron microscope (SEM) evaluation. All specimens were viewed at coronal, middle, and apical third of the root canal for evaluation of smear layer removal. The magnification used for smear layer analysis was $1000 \times$. Smear layer on the canal wall was evaluated using Torabinejad scoring system ${ }^{8}$ (Table 1). The SEM images were assessed with the objective digital method described to determine the area of each image occupied by dentin tubules. Data were log-transformed to normalize the variance. Normality of the transformed data sets was confirmed by using the KolmogorovSmirnov test. Data sets were analyzed with analysis of variance and selected by post-hoc Tukey-Kramer multiple comparison tests to explore the effect of laser system, fiber type, and irrigants. The analysis included comparison between lased and nonlased samples and the various controls including sham irradiation. ${ }^{8}$

\section{RESULTS}

GI: Control specimen irrigated with 17\% EDTA shows debris and smear layer in the coronal, middle, and the apical third of the root canal surface (Fig. 1A showed only the apical third image).

GII and GIII: Specimen irradiated with Er,Cr:YSGG lasers at the coronal and middle third shows effective smear layer removal. Most smear layer was evaporated and dentinal tubules were clean and open (Figs 1B and C).

GIV: The canal walls of the apical third show clean root canal walls with smear layer evaporated, melted, fused, and recrystallized in most of the specimen, but little debris observed (Fig. 1D).

Smear layer scores for the coronal, middle, and apical thirds after prepared root canals with or without lasing are listed in Table 2.

Control group showed significant difference $(\mathrm{p}<0.010)$ with the experimental groups and between GII and GIII,

Table 1: Torabinejad scoring system

\begin{tabular}{ll}
\hline Score & Contents \\
\hline 1 & $\begin{array}{l}\text { No smear layer. No smear layer on the surface of the } \\
\text { canal, all tubules were clean and open. }\end{array}$ \\
2 & $\begin{array}{l}\text { Moderate smear layer. No smear layer on the surface } \\
\text { of the canal, but tubules contained debris. }\end{array}$ \\
3 & $\begin{array}{l}\text { Heavy smear layer. Smear layer covered the root } \\
\text { canal surface and the tubules. }\end{array}$ \\
\hline
\end{tabular}



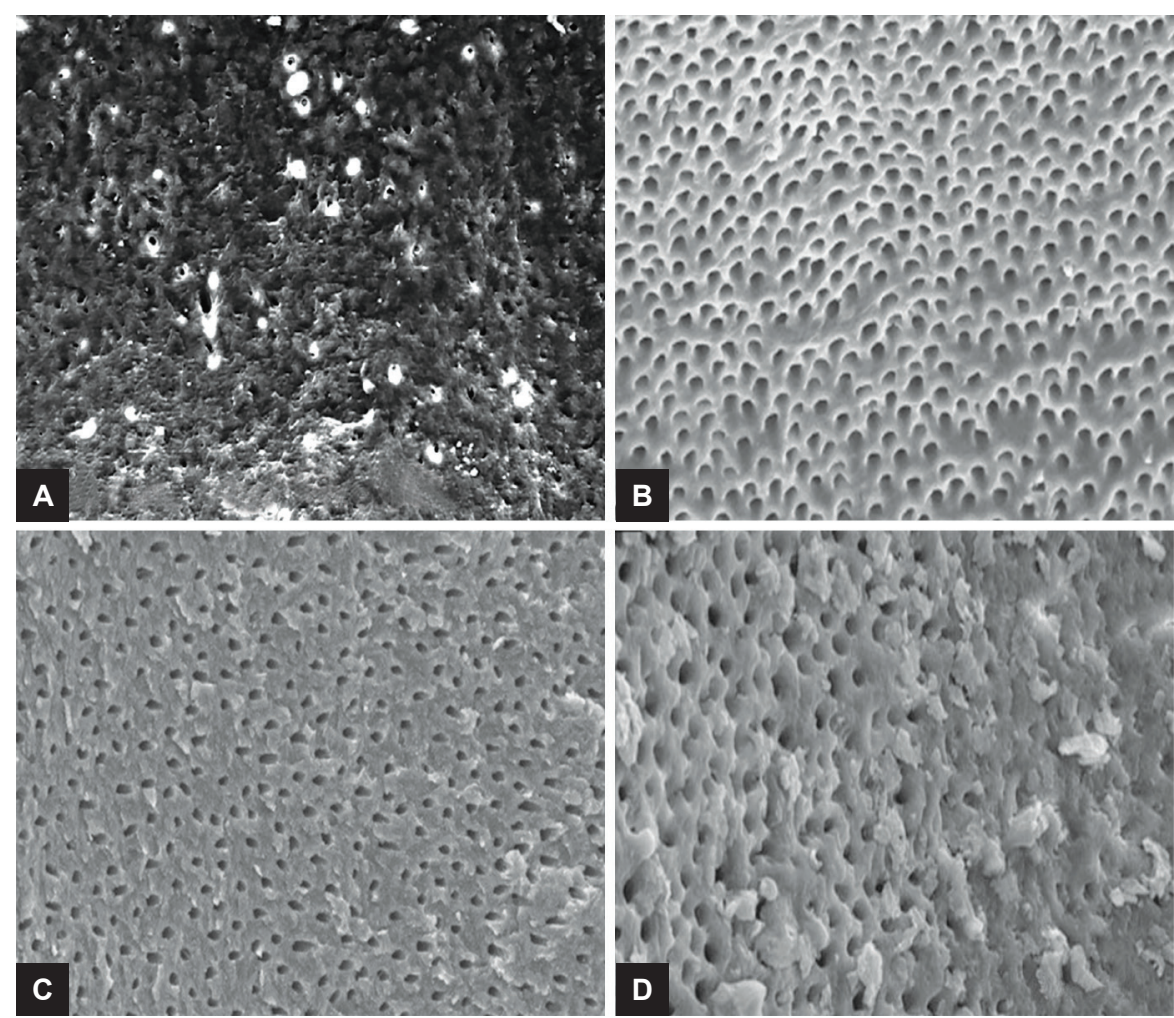

Figs 1A to D: Cornal Specimen irrigated with (A) 17\% EDTA; (B and C) Er,Cr:YSGG lasers; (D) evaporated, melted, fused, recrystallized canal walls

Table 2: Smear layer scores

\begin{tabular}{lllll}
\hline & \multicolumn{2}{c}{ Laser } & & \\
\cline { 2 - 4 } Groups & Mean & $\begin{array}{c}\text { Standard } \\
\text { deviation }\end{array}$ & Maximum & Minimum \\
\hline I & 1.40 & 0.69 & 1.35 & 0.42 \\
II & 1.56 & 0.53 & 1.96 & 1.15 \\
III & 1.67 & 0.50 & 2.13 & 1.63 \\
IV & 1.78 & 0.44 & 2.18 & 1.44 \\
\hline
\end{tabular}

GII and GIV, and GIII and GIV. There were no statistically significant differences in cleanliness of the canals.

\section{DISCUSSION}

The endodontic smear layer has been described as one that is formed during instrumentation, consisting of not only dentin, but also necrotic and viable tissue, including remnants of odontoblastic process, pulp tissue, and bacteria. The smear layer plays an important role in the lateral sealing of the root canal, by acting as an intermediate physical barrier that may interfere with adhesion and penetration of the root canal sealer into the dentinal tubules. Pashley et al described the smear layer as a porous structure, which was permeable to even large molecules like albumin. Mader et al had stated that the smear layer was a homogenous and weekly adherent structure, may slowly disintegrate, and dissolve around leaky filling margins, thus creating voids between root canal walls and filling material or sealer. Kennedy et al found that with the intact smear layer, apical leakage was significantly increased. The smear layer's presence plays a significant role in an increase or decrease in apical leakage. Its absence makes dentin more conducive to a better and closer adaptation of the gutta percha to the canal wall. The EDTA, which has the potential to remove the smear layer, did not produce the expected smear layerfree surface in the apical region of the canal. ${ }^{9}$

The Er,Cr:YSGG lasers provide wavelength of $2780 \mathrm{~nm}$, which acts through photoablation, since their wavelengths correlate closely with the absorption maximum of water contained by hydroxyapatite. When irradiated, water contained in the dental hard tissue evaporates instantaneously and, thereby, ablates the surrounding tissue with only minimal thermal side effects. This has been demonstrated in a study by Hibst and Keller. ${ }^{10}$ The development of flexible fiber tips allows the irradiation of even narrow and bent canals. With the introduction of the new conical radial firing fiber tip, the mode of light emission in the root canal has been improved. Owing to the conical shape of the fiber tip, the laser light is emitted in the form of broad cone with an angle of about $60^{\circ}$, according to the manufacture's information, allowing a more uniform coverage of the whole dentinal surface. ${ }^{4}$

Laser application that uses different wavelengths has also been proposed as adjuncts to conventional endodontic cleaning procedures. The undesirable side effects that occur with the use of lasers are moderate and within the limits, this technique is regarded to be safe. ${ }^{11}$ 
Previous studies have revealed the side effects that can be caused by the use of lasers in the root canal; these include the creation of ledges up to a canal curvature of $<10^{10,12}$ carbonization, cracks, collateral damage, and apical extrusion of solution. ${ }^{13}$ In our study, to avoid some of the side effects that are associated with the use of laser, the laser-driven irrigation was performed by hovering the laser tip, and during laser irradiation, the root canal was irrigated continuously to maintain the hydration level. ${ }^{8}$

In the present study, SEM evaluation revealed that the laser-treated group had the ability to remove the smear layer. This can be attributed to the ability of the laser-driven irrigation to create cavitation. Cavitation is defined as the formation of vapor or a cavity that contains bubbles inside a fluid. In water, use of a laser at ablative settings can result in the formation of large elliptical bubbles. These vapor bubbles can cause an expansion in volume to 1,600 times the original volume. This process can allow the irrigants to access the apical third of the canal more easily, which might assist in the cleaning of canals of various shapes. In addition, the cavitation bubbles expand, become unstable, and then collapse in what is termed an implosion. The implosion will have an impact on the surfaces of the root canal, causing shear forces, surface deformation, and the removal of surface material. Ebeling and Lauterborn observed shock waves that emanate from collapsing bubbles generated by laser pulse. These laser-generated pressure waves move at high speed and appear to enhance the action of endodontic irrigants in terms of removal of the smear layer. ${ }^{14}$

The mean rank scores for the smear layer were lowest in the control group, when compared with GII to GIV, which indicates the smear layer removal was poor in the absence of laser treatment. Blanken and Verdaasdonk ${ }^{12}$ showed that when an Er,Cr:YSGG laser was used with the endodontic fiber tip to activate a root canal irrigant, it results in the formation of bubbles as prescribed above. This cavitation effect is sufficient to remove a large dentin plug (Table 2).

Laser-driven irrigation used in GIV removed most of the smear layer; the mean rank scores for the smear layer in this group indicated that some remnants of organic components of the smear layer remained scattered on the surface of the root canal walls (Table 2). Based on the results of this investigation, it seems that laser-driven irrigation in which EDTA is used as the irrigant can remove the smear layer and debris effectively from the tip of root canal. The teeth in the GI (coronal third) and GII (middle third) showed the most effective removal of the smear layer, when compared with GIV (apical third). A conical laser fiber tip can be used to create cavitation in the root canal system.

\section{CONCLUSION}

Based on the findings of the present study and considering the limitations, irradiation by the Er,Cr:YSGG laser with conical fiber tip was more effective in smear layer removal from the root canal system.

\section{REFERENCES}

1. Wu MK, Wesselink PR. A primary observation on the preparation and obturation of oval canals. Int Endod J 2001 Mar;34(2):137-141.

2. Hülsmann M, Peters OA, Dummer PMH. Mechanical preparation of root canals: shaping goals, techniques and means. Endod Top 2005 Mar;10(1):30-76.

3. DiVito E, Peters OA, Olivi G. Effectiveness of the erbium:YAG laser and new design radial and stripped tips in removing the smear layer after root canal instrumentation. Lasers Med Sci 2012 Mar;27(2):273-280.

4. Gu LS, Kim JR, Ling J, Choi KK, Pashley DH, Tay FR. Review of contemporary irrigant agitation techniques and devices. J Endod 2009 Jun;35(6):791-804.

5. Weichman JA, Johnson FM, Nitta LK. Laser use in endodontics. II. Oral Surg Oral Med Oral Pathol 1972 Nov;34(5): 828-830.

6. Kimura Y, Yonaga K, Yokoyama K, Kinoshita J, Ogata Y, Matsumoto K. Root surface temperature increase during Er:YAG laser irradiation of root canals. J Endod 2002 Feb;28(2):76-78.

7. Takeda FH, Harashima T, Kimura Y, Matsumoto K. Comparative study about the removal of smear layer by three types of laser devices. J Clin Laser Med Surg 1998 Apr;16(2):117-122.

8. George R, Meyers IA, Walsh LJ. Laser activation of endodontic irrigants with improved conical laser fiber tips for removing smear layer in the apical third of the root canal. J Endod 2008 Dec;34(12):1524-1527.

9. Prabhu SG, Rahim N, Bhat KS, Mathew J. Comparison of removal of endodontic smear layer using $\mathrm{NaOCl}$, EDTA, and different concentrations of maleic acid - a SEM study. Endodontology 2003;15(1):20-25.

10. Hibst R, Keller U. Experimental studies of the application of the Er:YAG laser on dental hard substances: I. Measurement of the ablation rate. Lasers Surg Med 1989;9(4):338-344.

11. Peeters HH, Suardita K. Efficacy of smear layer removal at the root tip by using ethylenediaminetetraacetic acid and erbium, chromium: yttrium, scandium, gallium garnet laser. J Endod 2011 Nov;37(11):1585-1589.

12. Blanken J, Verdaasdonk R. Cavitation as a working mechanism of the Er,Cr:YSGG laser in endodontics: a visualization study. J Oral Laser Appl 2007 Apr;7(2):97-106.

13 Blanken J, De Moor RJ, Meire M, Verdaasdonk R. Laser induced explosive vapor and cavitation resulting in effective irrigation of the root canal. Part 1: a visualization study. Lasers Surg Med 2009 Sep;41(7):514-519.

14. Hmud R, Kahler WA, George R, Walsh LJ. Cavitational effects in aqueous endodontic irrigants generated by near-infrared lasers. J Endod 2010 Feb;36(2):275-278.

15. Blanken JW, Verdaasdonk RM. Cavitation as a working mechanism of the Er, Cr:YSGGlaser in endodontics: a visulatisation study. J Oral Laser Applic 2007;7:97-106. 